\title{
Educação Básica e Formação Docente em Cuba: Prós e Contras ${ }^{1}$
}

\author{
Basic Education and Teaching Formation in Cuba: \\ Advantages and Contras
}

Rose Meri Trojan²

Resumo:

A educação cubana tem se sobressaído pela sua efetividade em inúmeros estudos internacionais e, no contexto atual, toda a sua política educacional encontra-se vinculada ao ambicioso projeto de universalização da educação superior, no qual se destaca o modelo de formação docente inserido em todos os cursos de graduação. Esse modelo de formação tem como elementos fundantes a unidade entre educação e instrução e a articulação entre estudo e trabalho, o que o torna uma referência para estudo. Além disso, Cuba apresenta uma única instituição formadora para os docentes da educação básica-o Instituto Superior Pedagógico
- e um modelo único de formação, admitindo além da via presencial apenas a semipresencial. Para que a educação cumpra sua função social, importa sobremaneira avaliar em que medida tais propostas atendem às expectativas e necessidades apresentadas pelas demandas de formação, tendo em vista a qualidade do ensino. Esse artigo apresenta uma análise do tema em questão, indicando possibilidades, que deverão ser objeto de aprofundamento. O objetivo é, por meio de estudos comparados, contribuir para a busca de soluções dos problemas apresentados pelas atuais políticas de formação dos professores com vistas a uma educação de qualidade.

Palavras-chave: educação comparada; formação docente; política educacional cubana.

\footnotetext{
'Pesquisa sobre "Políticas de formação de professores para as séries iniciais do ensino fundamental: um estudo comparado sobre as propostas do Brasil e de Cuba" financiada pelo convênio CAPES/MES Ministerio de la Educación Superior de Cuba, realizada no período 2006/2008.

2Professora do Programa de Pós-Graduação em Educação da UFPR e pesquisadora do Núcleo de Políticas, Gestão e Financiamento da Educação da UFPR.

rosetrojan@uol.com.br
} 
Abstract:

Cuban education has stood out by its effectiveness in innumerous international studies and, in the present context, all its educational policy finds itself tied to the ambitious project of universalizing of the superior education, where the model of teaching formation inserted in all graduation courses stands out. This model of formation has as established elements the unity between education and instruction and the articulation between study and work, which makes it a reference for study. Besides, Cuba presents an unique formation institution for teachers on basic education - the Superior Pedagogical
Institution - and an unique model of formation, admitting besides the presential mode only the semi-presential. In order for education to fulfill its social functional, it is important to measure to what extent such proposals attend the expectations and necessities presented by the formation demands, having on sight the quality of education. This article presents an analysis of this theme, indicating possibilities that will have to be object of further research. The goal is, through comparative studies, to contribute to the search of solutions presented by actual policies of teaching formation in view of an education of quality.

Key words: comparative education; teachers formation; Cuban educational policy. 


\section{Introdução}

A educação cubana, a partir da revolução de 1959, desenvolveu uma trajetória que partiu de uma situação precária - com analfabetismo e falta de professores, e alcançou, no século XXI, uma invejável condição, agregou a erradicação do analfabetismo, universalização da educação secundária e um projeto de inclusão de todos na educação superior. No âmbito das avaliações realizadas por organismos multilaterais, como a UNESCO ${ }^{3}$, tem se sobressaído pela efetividade e pelos altos índices de proficiência dos alunos.

No contexto atual, toda a política educacional cubana encontra-se vinculada ao projeto de universalização da educação superior, no qual se destaca o modelo de formação docente. Esse modelo de formação - para todos os níveis, da educação infantil à educação superior - tem como elementos fundantes a unidade entre educação e instrução e a articulação entre estudo e trabalho, o que torna esse modelo uma referência para estudo.

Cuba apresenta uma única instituição formadora para os docentes da educação básica e um modelo único de formação, que admite além da via presencial apenas a via apenas semipresencial. Para que a educação cumpra sua função social, o modelo cubano tem defendido a articulação entre formação docente e ensino, entre educação e estudo e entre pesquisa e trabalho. Essa articulação apresenta-se como um dos motivos pelos quais a educação cubana tem apresentado resultados tão positivos.

Esse artigo toma como ponto de partida o plano de educação desenvolvido por Cuba a partir da década de 1960 e, partindo do atual estágio de desenvolvimento do projeto de universalização da educação superior, apresenta um panorama da formação docente e sua proposta de atuação na educação infantil, primária, secundária e superior.

\section{A Educação em Cuba}

Ao contrário do quadro da educação no mundo atual - que apresenta cerca de 860 milhões de analfabetos e 120 milhões de crianças sem escola, Cuba apresenta quadro diverso, pois já atende toda a demanda do acesso à educação básica. Desde a Campanha Nacional de Alfabetização de 1961 houve um esforço contínuo para superar esse desafio, chegando hoje à invejável condição de desencadear a proposta de universalização da educação superior. Desse modo:

En un inicio, estos centros de formación de maestros [escuelas de formación de maestros primarios que sustituyeron a las antiguas Escuelas Normales de Maestros] estuvieron en las montañas; después, la Revolución creó escuelas de formación de maestros en cada provincia, a las que se ingresaba con la educación primaria culminada y, más adelante, cuando las condiciones de desarrollo lo propiciaron, el nivel de ingreso fue con la secundaria básica terminada. (...) A partir de 1976, los institutos superiores pedagógicos construidos como centros universitarios independientes, conformaron una red de instituciones dirigida a la cobertura de docentes para lograr la universalización hasta el nivel medio y superior (GÓMEZ GUTIERREZ, 2006, p. 6-7).

Até 1959, Cuba contava com um sistema educacional precário e um alto índice de analfabetismo, pois: "A questão dos interesses norte-americanos na ilha requeria alguns administradores, empregados do ramo turístico, comerciantes e outros profissionais. O resto da população estava além das preocupações educacionais da classe governante e também da capacidade de absorção do sistema educacional" (PUIGGRÓS, 1992, p. 110). Assim, em 1958, o quadro educacional de Cuba apresentava um milhão de analfabetos absolutos, mais de um milhão de semi-analfabetos, 600 mil crianças sem escola e 10 mil professores sem trabalho (PUIGGRÓS, 1992, p. 112-113).

${ }^{3}$ Entre outros estudos, ver: CASTRO, Cláudio de Moura. Escolas feias, escolas boas? Ensaio, Rio de Janeiro, v.7, n. ${ }^{\circ}$ 25, p. 342-354, out./dez. 1999. 
A partir da revolução cubana de 1959, a educação passou a receber tratamento prioritário. Assim é que, a partir de uma Campanha Nacional de Alfabetização, em 1961, "erradicou-se o fenômeno do analfabetismo e deu-se início a uma redistribuição em grande escala da educação" (PUIGRÓSS, 1992, p. 113). Obtido esse primeiro êxito, o governo cubano passou a investir na continuidade da escolarização para todos e, paralelamente, na formação docente. De um início - quando não contava com a quantidade necessária de professores - desenvolvido pelo movimento de Maestros Voluntarios, passou à organização de cursos acelerados para preparação de professores emergentes e, gradativamente, para uma formação de nível médio e depois superior (GÓMEZ GUTIÉRREZ, 2006, p. 5).

\section{Estrutura e Organização do Sistema Educacional}

Em Cuba, todo o processo de organização da educação nacional é centralizado a partir de um sistema nacional unificado. Esse sistema é facilitado pela pequena extensão territorial - Cuba é um arquipélago formado por duas grandesilhas, entre outras pequenas perfazendo $110.860 \mathrm{~km} 2$, habitadas por 11 milhões de pessoas. A existência de um sistema nacional constitui-se em um instrumento fundamental na definição das políticas e normas comuns para garantir a unidade e efetividade das políticas e planos definidos, além da igualdade na qualidade de toda a educação ofertada, que é inteiramente pública e gratuita. Para tanto, "O sistema educacional cubano se apóia nos princípios do caráter massivo da educação; no princípio da vinculação estudo e trabalho; da participação de toda a sociedade nas tarefas da educação do povo; da co-educação e no princípio da gratuidade do ensino em todos os niveis" (FREITAS, 1998, p. 216).

Esses princípios traduzem a prioridade dadaà educação. Esta estáinserida num projeto nacional mais amplo, cujo objetivo é garantir, além do direito à educação, o direito à saúde, à moradia e ao emprego, para todos. O cumprimento dessas prioridades tem garantido ao povo cubano, apesar das grandes dificuldades econômicas, uma educação de qualidade; qualidade que tem reconhecimento nacional e internacional.

Entretanto, ainda que existam espaços institucionais para discussão, planejamento e avaliação em todos os níveis e âmbitos da rede de ensino - como os Coletivos Municipais e os Conselhos de Escola -, as decisões são centralizadas e partem das instâncias superiores. Por exemplo, ainda que baseado em um diagnóstico nacional, o novo modelo de escola secundária básica - correspondente às séries finais do ensino fundamental no Brasil foi elaborado por um coletivo de professores da Direção Nacional de Secundária Básica e do Instituto Central de Ciências Pedagógicas, para "cumplir el encargo planteado por el Comandante Fidel Castro" (MINED, 2007, p. 5). Mas, ao contrário do que acontece na América Latina, particularmente no Brasil, o processo de centralização inclui a garantia de manutenção e financiamento de toda a rede em igualdade de condições.

A estrutura do ensino no país está organizada de acordo com o modelo europeu: educação infantil, pré-escolar, primária, secundária e superior. Compõe-se de instituições específicas para cada um dos níveis e faixas etárias correspondentes: círculo infantil (zero a quatro anos de idade); pré-escolar (cinco anos), escola primária (seis a 11 anos); secundária básica (dez a 12 anos); pré-universitária, escola de ofícios, secundária obrero-campesina e instituto politécnico (15 a 17 anos); universidades, centros universitários e institutos superiores.

Mesmo tendo atingido a universalização do ensino secundário, esta estrutura mantém a modalidade de educação de adultos para enriquecimento cultural, re-qualificação profissional e para inserção daqueles que desistiram ou não chegaram a ingressar na idade própria no ensino superior, por meio dos chamados "programas de superação". 
Apesar do sistema nacional unificado e da centralização, em decorrência do princípio da união entre ensino e trabalho, a educação superior está dividida entre oito ministérios, um escritório, um comitê e um instituto nacional. O MES é responsável pela gestão das universidades e os demais pelos institutos superiores, responsáveis pela formação dos profissionais que atuam na sua área. Por exemplo: o MINSAP é responsável pela formação dos profissionais da saúde nos institutos superiores de medicina e enfermagem; o INDER, pelos atletas e professores de educação física, nos institutos superiores de cultura física; e assim por diante.

\begin{tabular}{|c|c|c|}
\hline Sigla & $\begin{array}{c}\text { Organismos } \\
\text { Responsáveis }\end{array}$ & Áreas de Estudo \\
\hline MES & $\begin{array}{l}\text { Ministerio de la } \\
\text { Educación Superior }\end{array}$ & $\begin{array}{c}\text { Ciências Técnicas, Ciências } \\
\text { Naturais e Matemáticas, } \\
\text { Ciências Sociais e } \\
\text { Humanísticas, Ciências } \\
\text { Agropecuárias e Economia. }\end{array}$ \\
\hline MINED & $\begin{array}{l}\text { Ministerio de la } \\
\text { Educación }\end{array}$ & Ciências Pedagógicas \\
\hline MINSAP & $\begin{array}{l}\text { Ministerio de la } \\
\text { Salud Pública } \\
\end{array}$ & Ciencias Médicas \\
\hline MIC & $\begin{array}{c}\text { Ministerio de la } \\
\text { Informática y de las } \\
\text { Comunicaciones }\end{array}$ & Informática e Comunicações \\
\hline MINCULT & $\begin{array}{c}\text { Ministerio de la } \\
\text { Cultura }\end{array}$ & Arte \\
\hline CITMA & $\begin{array}{c}\text { Ministerio de la } \\
\text { Ciencia, Tecnología } \\
\text { y Medio Ambiente }\end{array}$ & $\begin{array}{c}\text { Ciencia e Tecnología } \\
\text { Nuclear }\end{array}$ \\
\hline INDER & $\begin{array}{l}\text { Instituto Nacional } \\
\text { de Deporte, Cultura } \\
\text { Física y Recreación }\end{array}$ & Cultura Física \\
\hline ONDI & $\begin{array}{l}\text { Oficina Nacional de } \\
\text { Diseño Industrial }\end{array}$ & $\begin{array}{l}\text { Desenho Industrial e } \\
\text { Informacional }\end{array}$ \\
\hline MININT & $\begin{array}{l}\text { Ministerio del } \\
\text { Interior }\end{array}$ & Ciencias Militares \\
\hline MINFAR & $\begin{array}{l}\text { Ministerio de las } \\
\text { Fuerzas Armadas } \\
\text { Revolucionarias }\end{array}$ & Ciencias Militares \\
\hline MINREX & $\begin{array}{l}\text { Ministerio de } \\
\text { las Relaciones } \\
\text { Exteriores }\end{array}$ & $\begin{array}{l}\text { Relações Intenacionais } \\
\text { (pós-graducação) }\end{array}$ \\
\hline & $\begin{array}{l}\text { Comité Central del } \\
\text { Partido Comunista } \\
\text { Cubano }\end{array}$ & $\begin{array}{l}\text { Ciencias Políticas } \\
\text { (pós-graducação) }\end{array}$ \\
\hline
\end{tabular}

Fonte: VELA VALDEZ, 2006.

O MINED é responsável por toda a rede de ensino e pela formação de todos os docentes da educação básica - que atuam nas escolas infantis, primárias e secundárias como regentes de turma - nos institutos superiores pedagógicos e sedes universitárias municipais. Mas, os instrutores de artes, educação física, informática e língua estrangeira, que não são regentes de turma, formam-se nos institutos ou universidades que formam os profissionais da área - os artistas, os atletas, os técnicos em informática e os literatos. O que garante a unidade nacional é a definição de uma política nacional e um modelo pedagógico igual para todos os cursos de nível superior. Ainda assim, é possível verificar certo distanciamento entre as instituições, as quais atuam de forma independente da graduação à pós-graduação.

\section{Formação de Professores para a Educação Básica}

Atualmente, a formação dos professores pra a educação infantil, primária e secundária em Cuba é realizada integralmente em cursos de graduação plena de nível superior, universitário. O locus dessa formação é composto pelo Instituto Pedagógico Latinoamericano y Caribeño, articulado com os Institutos Superiores Pedagógicos Enrique José Varona e Héctor Piñeda, localizados na cidade de Havana e com dezesseis universidades pedagógicas distribuídas em todas as províncias cubanas (MARIÑO SÁNCHEZ et al, 2004, p. 3).

Os princípios gerais da política de formação docente são: a responsabilidade total do Estado pela formação inicial e continuada, por meio da gratuidade, garantia de emprego e formação contínua para todos os professores em exercício; instituições universitárias específicas de tempo integral e duração de cinco anos; e um sistema integrado das instituições universitárias com a escola. Além da formação inicial e continuada, essas instituições são responsáveis pela investigação educativa e elevação do potencial científico do seu território de abrangência (MARIÑO SÁNCHEZ et al, 2004, p. 3).

O desenho dos cursos de graduação apresenta um novo modelo, cujo programa geral de estudos obedece aos seguintes princípios: diagnóstico integral do aluno; processo de 
busca ativa do conhecimento pelo aluno; concepção de um sistema de atividades de estímulo ao desenvolvimento do pensamento reflexivo e da autonomia; orientação da motivação para aprender; estímulo à formação de conceitos teóricos e capacidade para resolver problemas; integração dos processos de interação do individual com o coletivo no processo de aprendizagem; atendimento das diferenças individuais; e vinculação entre os conteúdos de aprendizagem com a prática social (GONZÁLEZ, 1996, p. 164).

Os cinco anos de formação se dividem em duas etapas. A primeira, de caráter teórico-intensivo, tem como objetivo preparar os estudantes para o trabalho universitário independente e uma adequada formação psicológica, pedagógica e sociológica, que permita iniciar sua atividade docente. Segundo o Ministro da Educação:

... los estudiantes - después de una primera etapa de formación intensiva de un año de duración en que se habilitan para el ejercicio docente - reciben su formación académica en estrecha vinculación con la actividad profesional-investigativa que realizan en las escuelas de nivel para el que se forman, donde asumen la atención responsable de un grupo de alumnos - según el modelo de enseñanza correspondiente - bajo la atención de un tutor - que es un licenciado que le guiará a lo largo de su carrera tanto en la ayuda en sus estudios universitarios como en su formación profesional integral - y del conjunto del colectivo pedagógico de esos centros, vinculados a la actividad real del medio escolar y comunitario, al cual contribuyen a desarrollar de forma decisiva (GÓMEZ GUTIÉRREZ, 2006, p.15).

Então, a partir do segundo ano, os estudantes são encaminhados para uma escola considerada como micro-universidade que, em conjunto com sedes universitárias criadas nos municípios, garante a formação geral, acadêmica, laboral e investigativa dos estudantes. É importante destacar que, nessa proposta de formação, a pesquisa ocupa um lugar de destaque, focalizada na escola e a partir do trabalho realizado pelo estudante. Desse modo: "En la escuela tiene lugar la interacción de los maestros que se forman con los docentes de experiencia ya en ejercicio" (MARIÑO SÁNCHEZ et al., 2004, p. 6-9).

Assim, após o primeiro ano de estudos intensivos, a continuidade da formação se articula com a prática docente nas escolas escolhidas como micro-universidades, nas quais os estudantes são orientados e assessorados pelos professores mais experientes. Além disso, contam com professores tutores das sedes universitárias municipais, realizam pesquisas, estudos independentes orientados e freqüentam as aulas organizadas através de conferências, seminários e cursos. Essa nova concepção de formação docente tem como finalidade: aproximar a formação docente dos lugares onde os estudantes vivem e desenvolvem o seu trabalho; oferecer maiores possibilidades de acesso por meio de novas fontes de ingresso; e fortalecer a missão de formar verdadeiros educadores (MARIÑO SÁNCHEZ et al., 2004, p. 9).

Tal concepção é parte integrante do programa de Universalización da la Educación Superior, que tem como meta garantir o acesso ao ensino superior para todos os cubanos em 10 anos. Essa nova formação é adotada em todas as carreiras profissionais e envolve também uma proposta de formação docente para atuação no nível superior de todas as instituições de nível superior.

Essas mudanças tiveram início em 1991, com o processo de diagnóstico sobre o pessoal docente em exercício e com o processo de formação existente que embasou a definição dos princípios gerais da nova proposta. Entre os quais, destacamos:

- Lograr que la formación se realice en el trabajo y para el trabajo;

- El aumento de la preparación pedagógica, sociológica y psicológica de los estudiantes y el fortalecimiento de los conocimientos y habilidades para conocer con profundidad a los educandos con los cuales trabajarán;

- Lograr que los egresados de estas carreras sean, ante todo, pedagogos y que ello los distinga como profesionales universitarios (GÓMES GUTIÉRREZ, 2006, p.8). 
Finalmente, cabe salientar que o sistema cubano, atualmente, conta com 13 institutos, 199 sedes municipais e 5476 (escolas) microuniversidades para um total de 81.838 matrículas, 20.664 professores e 19.026 tutores (uma relação média de 1 tutor para cada 5 estudantes). Além disso, os estudantes têm garantido o suprimento de todo material científico-pedagógico e contam com a garantia de emprego e formação permanente após a conclusão do curso (HORRUTINIER, 2004, p.8).

Os Institutos Superiores Pedagógicos são responsáveis pela formação inicial e permanente dos profissionais da educação, pela pós-graduação, pesquisa e extensão universitária. As sedes municipais, articuladas com um instituto ou micro-universidade, organizam todas as atividades do processo educativo e, para isso contam com televisão e vídeo em cada sala de aula, laboratórios de computação, biblioteca e equipe pedagógica para realizar encontros, cursos, trabalhos independentes, videoconferências, pesquisas, orientação com professores, tutoria, atividades pedagógicas com os alunos da escola e avaliação dos estudantes.

Essa proposta dos institutos ou universidades pedagógicas, que separam o locus da formação docente das universidades e realizam as demais graduações - as primeiras regidas pelo Ministério da Educação e as segundas pelo Ministério da Educação Superior - merece um estudo mais detalhado. Porém, essa questão extrapola os limites definidos para o presente texto.

$\mathrm{O}$ ponto a ser aqui destacado, refere-se à relação entre teoria e prática no âmbito da formação inicial e continuada do pessoal docente em Cuba. Afinal, esses docentes demonstram uma nova possibilidade para a superação da dicotomia entre trabalho e ensino, a qual deverá ser comparada com a proposta brasileira. Na proposta cubana, a relação entre teoria e prática se estabelece a partir dos problemas apresentados na prática escolar, cujo tratamento deverá nortear os estudos e as pesquisas dos estudantes e seus professores.
Ao contrário da maioria dos cursos de graduação plena no Brasil, - com duração de quatro anos - em Cuba, a formação superior de cinco anos é significativa no que se refere a uma análise da qualidade. Em primeiro lugar, possibilita uma formação teórica mais sólida e aprofundada e, em segundo lugar, a relação entre teoria e prática se realiza, efetivamente, ao longo de todo o curso, combinando ensino e trabalho. É necessário salientar também que o primeiro ano de estudos, destinado para formação teórica intensiva, é cursado em tempo integral com carga horária de 6 horas ao dia, o que corresponde à carga horária de dois anos de curso em nosso país, cuja jornada diária é de quatro horas (FREITAS, 1998, p. 225).

Os estudos acadêmicos são orientados por um professor-tutor para cada cinco alunos, em média, situação que permite uma relação de ensino-aprendizagem e uma condição de avaliação com excelentes possibilidades. Já no início do curso, o tutor acadêmico elabora com o estudante um plano de estudos que será acompanhado durante todos os anos de formação. Esse vínculo que se estabelece entre tutor e estudante é fundamental para evitar rupturas, desvios e problemas de continuidade.

Dessa forma, juntamente com a orientação complementar oferecida pelo professor-tutor da escola, o estudante articula os estudos com o trabalho através do contato permanente e direto com a realidade escolar, o que permite inverter a tradicional relação teoria-prática descrita como mera aplicação da teoria, em atividades pontuais de estágio e prática de ensino.

Esse desenho curricular é formado por três componentes articulados - o acadêmico, o laboral e o investigativo - que destacam a pesquisa como uma das atividades desenvolvidas pelos próprios estudantes ao longo de todo o curso, possibilitando uma estreita vinculação com a atividade acadêmica e profissional, não apenas no processo de formação inicial, mas como um meio de educação permanente (ZILBERSTEIN, 2000). 
O programa de formação docente está focalizado principalmente na Didática, reafirmando a centralidade do processo de ensino e aprendizagem e "expresándose en el mismo la unidad entre instrucción, enseñanza, aprendizaje, educación, formación y desarrollo" (TORUNCHA, 2005, p. 11).

Portanto, o ensino não deverá levar os estudantes à prática pela prática, mas "promover que en la unidad dialéctica teoríapráctica, se apropien de manera consciente de generalizaciones teóricas que les permitan 'operar' con conceptos, leyes, establecer nexos y relaciones; todo lo cual favorecerá que el aprendizaje adquiera significado y sentido para ellos" (TORUNCHA, 2005, p.9).

\section{Educação Superior}

O plano de universalização da educação superior de Cuba, implantado em 2003, tem como meta, integrar todos os jovens de 18 a 25 anos na universidade num prazo de dez anos e, por meio dos chamados "programas de superação", incluir os trabalhadores que, por qualquer motivo, abandonaram os estudos antes de concluir um curso superior (CRUZ TEJAS, 2004).

O Sistema de Educação Superior de Cuba garante educação superior a todos os estudantes que concluem o ensino secundário pré-universitário no $12^{\circ}$ ano de estudo ou tenham formação equivalente, e sejam aprovados no exame de ingresso. Caso não seja aprovado, o estudante é encaminhado para programas de superação.

Atualmente, a rede de ensino superior conta com 65 instituições, incluindo universidades e institutos superiores, e 3.150 SUM, sedes universitárias municipais, que funcionam em escolas, locais de trabalho e outros espaços alternativos (VELA VALDÉZ, 2006).

De acordo com o Ministro da Educação Superior, no início do ano letivo de 2006-07, $58,35 \%$ dos jovens de 18 a 25 anos estavam matriculados em algum curso superior, perfazendo um total de 620.997 matrículas, distribuídas nos distintos ministérios que se ocupam da formação de nível superior. A pós-graduação stricto-sensu é constituída de 140 mil matrículas no mestrado e cinco mil no doutorado, sem contar com os profissionais que realizam seus cursos no exterior. Além desses, atende também 32 mil estudantes estrangeiros de 122 nacionalidades que realizam estudos de graduação e pós-graduação no país, mediante convênios. A evolução das matrículas de 2000 a 2007 demonstra o desenvolvimento do processo de inclusão dos jovens no plano estabelecido, destacando-se $\mathrm{o}$ incremento ocorrido nos últimos anos, quando se inicia o programa de universalização da educação superior no país.

Tabela 2. Evolução das matrículas no Ensino Superior Cuba $-2000 / 2007$

\begin{tabular}{|c|c|}
\hline Ano Letivo & Matrículas \\
\hline $2000-2001$ & 137.000 \\
\hline $2001-2002$ & 160.000 \\
\hline $2002-2003$ & 211.184 \\
\hline $2003-2004$ & 300.000 \\
\hline $2004-2005$ & 380.000 \\
\hline $2005-2006$ & 510.000 \\
\hline $2006-2007$ & 620.000 \\
\hline
\end{tabular}

Fonte: VELA VALDÉZ, 2006.

Para atender a essa demanda, o sistema conta com 120 mil professores, uma média de um professor para cada cinco estudantes - considerando o modelo pedagógico adotado que, além dos docentes, inclui um tutor acadêmico. Deste total, 32,5 mil são professores de tempo integral e 87,5 mil de tempo parcial, ou seja, profissionais que atuam na sua área específica e foram "categorizados" como docentes e/ou tutores mediante um curso de especialização e um exame, exercendo a docência no período noturno nas SUM.

Para atender o programa de universalização da educação superior, considerando as matrículas dos jovens e dos programas de superação - que incluem a graduação e a pósgraduação - são ofertados 95 cursos para as diferentes carreiras profissionais.

Os professores que atuam nos cursos superiores recebem uma formação pedagógica na sua própria instituição de formação. De 
modo semelhante ao que ocorre no Brasil onde os cursos de bacharelado agregam uma formação pedagógica a fim de possibilitar a licenciatura em matérias específicas como Português, Matemática, Geografia, etc. nas $5^{\mathrm{a}}$ a $8^{\mathrm{a}}$ séries e ensino médio - em Cuba, os estudantes das distintas carreiras (agronomia, veterinária, medicina, engenharia, etc.) formamse professores do ensino superior em sua área de habilitação, na forma de uma especialização que pode ser integrada ou posterior à formação. Esse é um programa implantado no âmbito do programa de universalização da educação superior, o qual apresenta um avanço em relação à formação de professores, pois propõe preparar os profissionais que irão atuar na docência do ensino superior. No Brasil a preocupação com essa especificidade é recente e, em geral, é ofertada apenas como opção nos cursos de pós-graduação, sendo que a legislação nacional não faz nenhuma exigência nesse sentido.

\section{Educação Secundária}

A educação secundária é constituída de duas etapas: secundária geral e pré-universitária, ambas já universalizadas em todo o território cubano. Na segunda etapa, o estudante pode optar por um curso técnico de nível médio, que também garante o acesso ao nível superior. No que se refere à primeira etapa:

La Educación Secundaria Básica trabaja en el presente curso escolar con la convicción de cumplir las metas y objetivos propuestos por el MINED, cumpliendo con 2 principios básicos: la relación 1/15 alumnos para cada docente y el uso eficiente de las nuevas tecnologías (MINED, 2007, p. 6).

Segundo Fidel Castro, em discurso pronunciado em oito de setembro de 2003, no marco da revolução educacional, o uso da televisão, do vídeo e da computação se converteram em fatores insubstituíveis na busca constante por elevar a qualidade educacional. Para isso, são lotados técnicos em todas as escolas, responsáveis pela capacitação dos docentes e pelos laboratórios dos alunos, também, dentro da relação 1/15 (MINED, 2007).

A relação de um docente para cada 15 alunos na escola secundária, aliada a jornada de tempo integral na mesma escola com $50 \%$ para atividades coletivas extra classe, representa uma melhoria significativa das condições de trabalho docente, no sentido de garantir a qualidade do ensino. Porém, o fato do mesmo professor acompanhar o mesmo grupo de 15 alunos durante os três anos de curso é uma questão que merece maior investigação para avaliar o seu impacto.

No entanto, a escola secundária básica foi totalmente reformulada a partir dos anos 2000, a favor de uma nova concepção de professor: o PGI - professor geral integral. Esse modelo segue a mesma concepção do professor primário (ou das séries iniciais do ensino fundamental, no Brasil), baseado na unidocência, ou seja, o mesmo professor ministra todas as matérias.

As funções do PGI, em relação ao seu grupo de 15 alunos, incluem: conseguir um profundo domínio das individualidades de seus alunos, suas necessidades, conflitos e interesses; realizar um diagnóstico, integral e fino de cada um deles a partir do expediente acumulativo do escolar; e responsabilizar-se pelas ações educativas de seu grupo, junto com os professores de Inglês, Educação Física, Instrutores de Arte e pais. (MINED, 2007)

Inicialmente, os professores da escola secundária básica - que haviam sido formados para ministrar uma disciplina específica - receberam uma formação para a nova função e, por meio do coletivo de professores e do material áudio-visual preparado para as aulas, assumiram a unidocência. Atualmente, é possível observar a formação das primeiras turmas de PGI em cursos específicos. Deste modo, ainda é cedo para avaliar os resultados desse modelo que contradiz uma tendência, observada no Brasil, de estender a especialização da docência para as séries iniciais. 


\section{Educação Primária}

Aescolaprimáriaadotaaconcepção domodelo de escola cubana a partir dos mesmos princípios já indicados na proposta de educação secundária, os quais propiciam condições favoráveis para levar a cabo um processo educativo de maior qualidade, a qual depende, fundamentalmente, da manutenção de um reduzido número de matrículas por sala (a referida relação 1/15), assim como da inserção da tecnologia educativa, constituída em complemento significativo para os processos instrutivos e educativos que se desenvolvem na escola (MINED, 2006).

A diversidade etária $e$ as etapas do desenvolvimento que se apresentam na escola primária a exemplo do modelo de ciclos de aprendizagem fundamentam um modelo pedagógico empenhado em garantir uma atenção pedagógica mais efetiva, considerando os objetivos e as metas mais gerais a alcançar em cada uma dessas etapas parciais de desenvolvimento. Os referidos momentos ou etapas de desenvolvimento são os seguintes: de cinco a sete anos (Pré-escolar ao segundo ano); de oito a dez anos (terceiro e quarto ano); e de 11 a 12 anos (quinto e sexto ano) (MINED, 2006).

Para atender às especificidades de cada etapa, a escola realiza reuniões mensais com o coletivo de professores para avaliar os resultados obtidos. O trabalho das comissões também determina e analisa as medidas definidas para solução dos problemas encontrados.

A estratégia de trabalho também é a mesma para toda a educação básica e deverá contemplar enquanto ações iniciais os seguintes aspectos: diagnóstico integral da instituição escolar e diagnóstico integral e fino do aluno, realizado pela comunidade escolar - da qual participam os professores e representantes dos pais e da comunidade (MINED, 2006).

A escola, considerada como microuniversidade, articulada com o Instituto Pedagógico Superior e a Sede Universitária Municipal de sua localidade, recebe e integra os estudantes dos cursos de formação docente ao seu corpo de profissionais, sempre orientados por um tutor categorizado, ou seja, um professor que já tem experiência de magistério, recebeu um bom conceito na avaliação de desempenho, participou de um curso de formação e foi aprovado em um exame de habilitação.

Las características del proceso docente en estas sedes permiten la adecuada combinación de encuentros presencialesconlosprofesoresuniversitarios, lautilización de materiales grabados en video y de la computación para el trabajo independiente, con un sistema evaluativo que toma en cuenta fundamentalmente el desempeño de los estudiantes en la actividad profesional para la cual se forman (SUÁREZ RAMOS, 2005).

Ao contrário do modelo brasileiro - que permite a formação dos docentes para a educação infantil e as séries iniciais do ensino fundamental em um mesmo curso - em Cuba, os cursos de formação são todos específicos para cada etapa e modalidade: educação infantil, ensino primário, ensino secundário básico, educação especial, educação de adultos, etc. A formação para atuar na organização do trabalho pedagógico e direção da escola se faz por meio de cursos de pós-graduação, em nível de especialização e, também, passam por procedimentos similares de categorização.

\section{Educação Infantil}

A partir de 1961, foram criados os círculos infantis, onde se recebiam crianças desde 45 dias de nascidos até os cinco anos, com o propósito de propiciar a incorporação da mulher no trabalho. Nessa etapa, o trabalho esteve dirigido principalmente para a saúde e a nutrição das crianças, para o incremento do número de instituições e para a preparação do pessoal que trabalharia nesses centros. Na década de 1970, criou-se o Instituto de la Infancia, as Escuelas Formadoras de Educadoras e a Comisión de Educación de Padres. Durante os anos 1980, implantou-se o primeiro programa deste nível de ensino, a Educação Pré-escolar foi integrada ao Ministério de Educação como parte do Sistema e se criou a Licenciatura em Educação Pré-escolar (MINED, 2008). 
A partir de 1990, paralelamente ao aperfeiçoamento do ensino pré-escolar por vias institucionais, começa o Programa "Educa a tu Hijo", para orientar a família das crianças que não freqüentavam os círculos infantis, e o Centro Latinoamericano de la Educación Preescolar (CELEP) foi criado para favorecer o intercambio de experiências, a investigação e qualificação docente (MINED, 2008).

O programa Educa a Tu Hijo se caracteriza por oferecer condições pedagógicas para a educação das crianças pequenas no seio da família, desde o seu nascimento até o ingresso na escola, incluindo orientação para o período de gestação. Os pais e parentes que se disponibilizam para cuidar e educar a criança recebem orientação pedagógica e psicológica, dirigida pela Dirección de Educación Preescolar del Ministerio de Educación, por meio de um programa de caráter interdisciplinar no âmbito da recreação, esporte, cultura, etc. Para isso, as pessoas se dirigem a uma instituição local - escola, centro social, ou outra - e, enquanto recebem formação, as crianças participam de atividades educativas.

\section{Considerações Finais}

O estudo comparativo é um excelente espaço para refletir sobre a educação e sobre a formação dos professores que deverão executá-la. A partir do estudo sobre a educação em Cuba aqui apresentado - tomando-se como princípio fundamental de comparação o postulado da igualdade e considerando-se os contextos econômicos, políticos, sociais e culturais de cada país - é possível identificar semelhanças e diferenças para estabelecer uma relação de simetria, na qual a diferença não signifique superioridade ou inferioridade, mas especificidade, possibilidades e limites, que se colocam a partir das condições próprias de cada país.

A partir do plano de educação desenvolvido por Cuba a partir da década de 1960 e do atual estágio de desenvolvimento do projeto de universalização da educação superior, destacam-se no panorama da formação docente e sua proposta de atuação na educação infantil, primária, secundária e superior: a organização e a estrutura do sistema de educação, o lócus da formação de professores, o modelo pedagógico de ensino e o de formação docente.

Sobre a organização e a estrutura, o sistema nacional de educação cubano garante unidade e igualdade em termos de acesso, permanência e condições materiais e pedagógicas para todos os estudantes em todos os níveis e modalidades de ensino de todo o país. Porém, a distribuição da responsabilidade entre vários ministérios pode levar a um distanciamento entre as várias áreas do conhecimento, ainda que, por essa mesma razão, garanta a articulação entre ensino, pesquisa e trabalho.

Os institutos superiores pedagógicos como locus central da formação de professores, articulados com as sedes universitárias municipais e as escolas, também garantem unidade de formação, por meio da padronização dos cursos ofertados e da metodologia adotada. Além disso, cabe destacar a relação entre ensino e trabalho, considerando a constituição do sistema e da rede escolar que inclui as instituições de educação básica e superior.

Omodelo pedagógico de ensino da educação básica, por sua vez, garante condições excelentes para a equipe de profissionais no que se refere à relação de um professor para cada 15 alunos, ao tempo integral de trabalho na mesma instituição, sendo que 50\% de tempo é destinado a atividades extra-classe, envolvendo todos os profissionais e representantes da comunidade. Essas condições garantem, além do trabalho coletivo em geral, o funcionamento dos conselhos escolares.

Paralelamente, o modelo pedagógico de formação - constituído de um ano de formação teórica em tempo integral, quatro anos de articulação entre ensino, pesquisa e trabalho e sistema de tutoria - possibilita inverter a relação teoria e prática na direção da superação do 
estágio como mera "aplicação da teoria". Destaca-se, ainda, a proposta de formação específica para formação dos docentes no ensino superior.

A partir das diferenças identificadas e da política educacional cubana - ainda que não se possa tomar o exemplo de Cuba como modelo a ser adotado no Brasil, dadas às especificidades de cada país - é possível, desde já, perceber a importância deste estudo para aprofundar o conhecimento de cada realidade e, em especial, o nosso autoconhecimento.

Referências Bibliográficas

CRUZ TEJAS, N. Retos y propuestas de la educación superior. Anais do IV Congreso Internacional de Educación Superior - La universidad por un mundo mejor - Havana - Cuba, 2004. (1 CD-rom)

FREITAS, H. C. L. Formação de Professores na Escola Cubana: o processo nas séries iniciais. In: GOERGEN, P.; SAVIANI, D. (orgs.) Formação de Professores: a experiência internacional sob o olhar brasileiro. Campinas, SP: Autores Associados; São Paulo: NUPES, 1998, p. 213-233.

GONZÁLEZ. Tendencias Pedagógicas Contemporáneas. Cuba: Centro de Intercambio Educacional Graciela Bustillos, 1996.

GÓMES GUTIÉRREZ, L. I. La Universalización de la educación superior pedagógica: impacto y proyecciones estratégicas sobre el sistema educacional cubano. Habana, Cuba: Ministerio de la Educación de la República de Cuba, 2006.

HORRUTINIER, P. El diseño curricular en la educación superior. Anais do IV Congreso Internacional de Educación Superior - La universidad por um mundo mejor - Havana - Cuba, 2004. (1 CD-rom) MARIÑO SÁNCHEZ, M. A.; SIERRA RICARDO, L.; LYVA SOLER, C. La Formación del profesor general integral: una experiencia de las universidades pedagógicas de Cuba. Anales del IV Congreso Internacional de Educación Superior - La universidad por un mundo mejor - Habana - Cuba, 2004. (1 CD-rom) MINED - Ministerio de Educación de Cuba, colectivo de autores de la Dirección Nacional de Primaria e Instituto Central de Ciencias Pedagógicas. Modelo de Escuela Primaria. Habana-Cuba, 2006.

MINED - Ministerio de Educación de Cuba, colectivo de autores de la Dirección Nacional de Secundaria Básica e Instituto Central de Ciencias Pedagógicas. Modelo de Escuela Secundaria Básica. Habana-Cuba, 2007.

MINED. Educación Preescolar. Disponível em: www.rimed.cu/preescolar/preescolar.asp Acesso em 23 de junho de 2008. Habana-Cuba, 2008.

PUIGGRÓS, A. Três artigos sobre a educação socialista. In: FRANCO, M. A. C. Estudos Comparados e Educação na América Latina. São Paulo: Livros do Tatu: Cortez, 1992, p.91-136.

SUÁREZ RAMOS, R. Formación de profesores, una tarea estratégica. Disponible em: www.cubaportal. org.es Acesso em 10 de novembro de 2007.

TORUNCHA, J.Z. Reflexiones acerca de la necesidad de establecer principios para el proceso de enseñanza aprendizaje: Retrospectiva desde la didáctica cubana. Habana, Cuba, 2005. (texto digitado) VELA VALDÉZ, J. (Ministro de la Educación Superior de Cuba.) Mesa Redonda de Apertura del Año Lectivo 2006-07. Habana-Cuba, 2006. (uma fita de vídeo)

ZILBERSTEIN, J. Didáctica integradora: una experiencia a partir de las raíces pedagógicas cubanas. In: Debates Americanos, No. 9, Enero - Junio, Cuba, 2000. 